Egypt. J. of Nutrition and Health Vol. 15 No. 2 July (2020)

\title{
Comparative study among Corn silk, Pumpkin Seeds, and Creatine to test the efficiency of physical activity in rat
}

\section{Mohammed H .Haggag; Naeem M Rabeh and Asmaa Z. Mohammed}

\author{
Nutrition and Food Sci. Dept, Faculty of Home Economics \\ Helwan Univ., Cairo-Egypt
}

\begin{abstract}
The present study was conducted to investigate the effect of corn silk,pumpkin seeds and creatine supplementation on kidney function, liver function, glucose, creatine kinase and lactate dehydrogenase in adult male rats subjeced to exercise training. Fifty male albino rats, were fed on basal diet for one week for adaptation. During the adaptive week all rats (except negative control group) were exposed to day after day forced treadmill running exercise for $10 \mathrm{~min}$. Rats were divided into two main groups, the first main group ( $n=10$ rats) was fed on basal diet only and served as negative control group. The second main group (exercised rats) were divided into 4 subgroups (10 rats each) as follows:-Subgroup 1: were fed on basal diet and had run for 10, 15, 20 and 25minutes(15 days for each time periodrespectively) to complete 60 days, and served as positive control group. And the rest of Subgroups (2-4) were fed on basal diet supplemented with $4 \%$ corn silk powder, $4 \%$ pumpkin seeds powder and $4 \%$ creatine powder, respectively as the same exercise of positive control subgroup. At the end of the experimental period (60 day), each subgroup were exposed to the exhausting treadmill test and the run time was recorded, then all experimental rats were scarified.From the obtained results we concluded that pumpkin seed have bioactive compounds that elevate the exercise performance, and prolong the exhaustive time, corn silk have a good effect in glucose level by increasing insulin level and recovering injured beta cells, and not via increasing glycogen or inhibiting gluconeogenesis, although creatine recorded the largest glycogen quantity in gastrocnemius muscles among supplemented groups, but it caused an elevation of ammonia,AST , and uric acid levels when exposed to exhaustive time test. So future studies are recommended to clarify creatine benefit in exercise field.The study advised to consume corn silk and pumpkin seed to prolong exercise time and accelerate recovery from exercise training.
\end{abstract}

Key words: Corn silk, Pumpkin seeds, Creatine supplementation, Creatinine, Treadmill ,Exercise.

\section{Introduction}

The purposes of performance studies are to increase exercise capacity and to shorten the recovery time after fatigue. In consideration of the side effects of Pharmacological drugs, such as safety and legality issues, dietary supplementsseem to be a better choice to treat exercise-induced fatigue, combinations of different biomarkers have been widely used (Finsterer and Drory, 2016). The diversity of nutrients or compounds from food factors or medical herbs could be investigated for their possible effect on exercise physiology and for understanding the different bioactivities that could be used for health promotion(Ching et al., 2015). Physical activity modifies the balance between oxidative stress and antioxidant defense mechanisms. For both athletes and fitness enthusiasts, the combination 


\section{Mohammed H .Haggag, et al}

of regular physical activity and antioxidant supplement may have important restorative effects on the body's oxidation reduction or redox balance (Araújoet al., 2013). Corn silk (Maydis stigma) is a waste material from corn cultivation, available in abundance, and possesses antioxidant, anti-fatigue, antitumor and anti-fungal activities (Ebrahimzadehet al., 2009 and Hu et al., 2010).

The seeds of pumpkin are generally considered to be agro-industrial wastes and discarded. In some parts of the world, the seeds are consumed raw, roasted or cooked, but only at the domestic scale. With the discovery of their richness in protein, fibers, minerals, polyunsaturated fatty acids and phytosterols, they are being regarded valuable for the food industry. Also, their beneficial effects on blood glucose level,immunity, and cholesterol, liver, prostate gland, bladder, depression, learning disabilities and parasite inhibition are being validated (Patel, 2013)Dietary supplementation with creatine (CrS) is popular in the sports and fitness industry, wherein CrS is believed to aid in the maintenance of high energy phosphate reserves during exercise. While certain mechanisms of action involved in improved physical exercise performance with CrS have been established (Gama, 2011 ).

The aim of the study was to investigate the effect of corn silk, pumpkin seeds and creatine supplementation on the exercise performance of adult male trained rats.

\section{Materials and Methods}

\section{Materials:}

Corn silk and Pumpkin seeds were purchased from Field Crops Research Institute, Ministry of Agriculture Giza, Egypt. Creatine powder, casein, vitamin mixture, mineral mixture and cellulose were purchased from El-Gomhoria Pharmaceutical Company, Cairo, Egypt. Rats: fifty young adult male albino rats of Sprague- Dawely Strain, weighting (150 $\pm 5 \mathrm{~g}$ ) were obtained from Animal House Colony of Vacsera, Helwan, Egypt. Kits for blood analysis were purchased from Gama Trade Company for Chemicals, Cairo, Egypt.

The Treadmill was purchased from Sports Equipment Store, Cairo, Egypt (YY-T900D Luxury electronic treadmill, Motor power 3,0HP Quality in Taiwan with an adjustable speed $(0,8-14.8 \mathrm{Km} / \mathrm{h})$, Running surface $1230 * 430 \mathrm{~mm}$, and expand dimensions $1620^{\star} 700^{\star} 1200 \mathrm{~mm}$ enabling forced exercise training and accurate testing of fatigue in rats.An easy-to-move wooden frame $(120 \times 45 \mathrm{~cm})$ was used, divided into nine cells to force the mice to run inside it and not leave the treadmill space

\section{Methods:}

Preparation of Dried Plants:-Fresh corn silk and pumpkin seeds were washed by using tap water and were dried using solar energy at the National Research Centre, Giza, Egypt for two days then grounded to get a fine powder. The sun rays enable the dried product to retain its nutrients as described by (Andritsoset al.,2003).Chemical composition of the tested materials:-Active component (phenolic-flavonoids) and antioxidant activity of corn silk and pumpkin seeds were determined chemically according to the method described by (Brand-Williams, et al., 1995)

\section{Experimental Design:-}

This study was carried out at the Animal House of Home Economic Faculty, Helwan University. Fifty male albino rats, were housed in well aerated cages under hygienic condition and were fed on basal diet for one week for adaptation. During the adaptive week all rats (except negative control group) were exposed to forced treadmill running exercise day after day for 10 min according to 


\section{Egypt. J. of Nutrition and Health Vol. 15 No. 2 July (2020)}

the method of (Daviset al., 2009). Body weight and feed intake for all rats had recorded. Feed Efficiency Ratio was calculated.

Rats were divided into two main groups, the first main group ( $n=10$ rats) was fed on basal diet only and served as negative control group. The second main group (exercised rats) were divided into 4 subgroups (10 rats each) as followed:-

1- Subgroup 1: were fed on basal diet and run for 10, 15, 20 and 25minutes (15 day for each time) for 60 day, respectively and served as positive control group

2-Subgroup 2: as the same of positive control subgroup with $4 \%$ corn silk powder.

3-Subgroup 3: as the same of positive control subgroup with $4 \%$ pumpkin seeds powder.

4-Subgroup 4: as the same of positive control subgroup with $4 \%$ creatine powder.

The exhausting time protocol:

At the end of the experimental period (60 day), each subgroup were exposed to the exhausting treadmill test and the run time was recorded, then all experimental rats were scarified. Blood samples were collected and centrifuged to obtained serum which was used for the biochemical analysis.

\section{Biochemical analysis of serum:}

Serum samples were used for the determination of glucose described by(Trinder, 1969 and Weissman and Klein, 1958), creatine kinase (Tietz, 1976), lactate dehydrogenase (Vassault et al., 1986), Aspartate aminotransferase (AST) (Schumann et al., 2002), Alanine aminotransferase (ALT) was determined in serum according to (Sherwin, 1984). Serum creatinine was determined according to (Murray etal., 1984), Serum Uric acid concentration was determined according to the method described by (Fossatiet al., 1980)Serum urea was determined according to (Kaplan etal., 1984), Serum malondialdehyde (MDA) was determined by the method of (Ohkawaet al., 1979), Serum Glutathion-s-trasferase(GST) was determined by the method of (Habiget al., 1974).

\section{Statistical analysis:-}

The results were statistically analyzed using computerized program SPSS . results were expressed as mean $\pm S D$.differences among groups were analyzed using analysis of variance (ANOVA) by Duncan's test .A p $<0.05$ was considered statistically different according to (Sendecor and Cochran, 1986).

\section{Results}

The total phenolic content of corn silk and pumpkin seeds are presented in Table (1) The results indicate that corn silk contained more phenolic components than pumpkin seeds except vanillin acid .

The data in table (2) shows the result of the radical scavenging activity for corn silk and pumpkin seeds which recorded high antioxidant activity $99.68 \%$ in $5 \%$ concentration compared to corn silk which recorded 84.07 in $5 \%$ concentration. In addition pumpkin seeds had higher percent of radical scavenging than corn silk of all concentration.

Table (3) recorded the effect of corn silk, pumpkin seeds, and creatine on feed intake, body weight gain, and feed efficiency ratio in male rats which were exposed to the exhaustive test according to the experimental training treadmill protocol. Results indicate that positive control group had fed on 


\section{Mohammed H .Haggag, et al}

basal diet throughout the experiment and was trained day after day for sixty days had non-significant increase on feed intake level compared to the negative control group.

Corn silk and creatine groups significantly increased feed intake compared to +ve group, otherwise pumpkin seeds group had no change in feed intake compared to ( +ve )group. The best group of all tested groups in feed intake was creatine group. Rats in +ve control group had significant decrease (BWG) compared to -ve control group. Corn silk group and pumpkin group significant decrease BWG compared to (+ve) control, on the other side creatine group significantly increased BWG compared to (+ve) group and recorded the best group findings.

Data in Table (3) showed that (FER) of rats in the positive control group was significantly decreased compared to -ve control group. Corn silk and pumpkin seeds had significant decrease in FER compared to +ve control group, while creatine group had significant increase in FER compared to +ve control group. The best result in (FER) of all tested group was creatine group.

As shown in Table (4) the effect of corn silk, pumpkin seed and creatine on (AST), illustrated significant increase in the (+ve) control group compared to the (-ve) control group. Rats fed on corn silk had non-significant decrease in AST compared to (+ve) control group. Whereas, rats fed on pumpkin seeds and creatine recorded significant increase in (AST) level compared to the (+ve) control group. Corn silk group marked as the best group among all tested groups. Alanine aminotransferase level of the (+ve) control group significantly decreased compared to (-ve) control group. Rats fed on corn silk had non-significant decrease compared to $(+v e)$ control group. While rats fed on pumpkin seeds and creatine noticed significant increase in ALT compared to (+ve) control group. Corn silk group recorded the best findings among all tested groups.

Results indicated that the positive control group had significant increase in ammonia level compared with the (-ve) control. While rats which fed on corn silk and pumpkin seeds had significant decrease in ammonia compared to (+ve) control group. Creatine group recorded significant increase among all tested groups and compared with (+ve) control group.

Table (5) showed the effect of corn silk, pumpkin seeds, and creatine on creatinine, urea, and uric acid level in male rats exposed to exhaustive test according to the experimental training treadmill protocol. Positive control rat group (+ve) fed on basal diet exposed till end of experiment to exhaustive treadmill test noticed that significant increase in creatinine level compared to (-ve) group. In addition all tested groups had significant decrease in creatinine level compared to the (+ve) control group. Urea level results had significant decrease in (+ve) control group compared to (-ve) group. Also all the tested groups had significant increase compared to (+ve) control group. Uric acid (UA) level in rats exposed to exhaustive time test had non-significant increase in (+ve) control group compared to (-ve) group. Rats fed on corn silk, pumpkin seed and creatine had significant increase in UA compared to the (+ve) control group. Pumpkin seeds group marked as the best group of all tested groups.

Table (6) showed the effect of corn silk, pumpkin seeds, and creatine on, glucose, creatine kinase, and lactate dehydrogenase level in the experimental animal. The result indicated that glucose level in the (+ve) control group was significantly increased compared to the (-ve) control group. Corn silk group and pumpkin group recorded significant decrease in glucose level compared to (+ve) group, however creatine group recorded significant increase compared to (+ve) control group. The best result recorded in corn silk group. Data of creatine kinase revealed that the (+ve) control group showed nonsignificant decrease compared with the (-ve) control group. The finding indicated that corn silk,pumpkin 


\section{Egypt. J. of Nutrition and Health Vol. 15 No. 2 July (2020)}

seed, and creatine showed significant increase compared with (+ve) control group, the best result among all tested groups were creatine group. Lactate dehydrogenase level in the (+ve) control group showed significant decrease compared to the (-ve) control group, but corn silk group, pumpkin seed, and creatine recorded significant decrease compared to (-ve) control group. The best result was corn silk group.

Table (7) showed the effect of corn silk, pumpkin seeds, and creatine on MDA and GST level in male rats exposed to exhaustive test according to the experimental training treadmill protocol. Rats in (+ve) control group fed on basal diet, recorded significant increase in MDA concentration compared to (-ve) control group. While rats in corn silk, pumpkin seed, and creatine groups had significant decrease when compared to (+ve) control group. Creatine group showed the best result among all tested group. The results revealed that GST was significantly decreased in (+ve) control group when compared to (-ve) control group, however rats fed on corn silk, pumpkin seed and creatine showed significant increase in GST level when compared with the (+ve) control group. The best result recorded in corn silk group among all tested group.

Table (8) recorded the average time consumed on exhaustive treadmill exercised rats. The result indicated that rats on corn silk and pumpkin seed groups recorded an average 35, $45 \mathrm{~min}$ respectively, whereas (+ve) control group fed on basal diet recorded an average 20 minutes, this Illustrates significant elongation of the average exhaustive time while rats on creatine group recorded $25 \mathrm{~min}$ in exhaustive treadmill test time illustrate which is not-significantly different compared to $(+\mathrm{ve})$ control group which recorded $20 \mathrm{~min}$ in exhaustive treadmill test time.

Table (9) recorded the effect of exposing to exhaustive treadmill time test on glycogen content in liver and gastrocnemius muscles of exercised rats. The result indicated that rats in (-ve) control group about glycogen content in liver was recorded the highest level compared to all groups while the same group recorded mild content of glycogen level in gastrocnemius muscle. Furthermore Creatine group showed high content of glycogen in gastrocnemius muscle compared to all groups followed by (+ve) control group, pumpkin seed, and (-ve) control group respectively. The same table shows the glycogen content in liver and gastrocnemius muscle when rats are not exposed to treadmill. The results indicated that (-ve) control group and corn silk group showed high glycogen content in liver of rat on non-exposure to exhaustive treadmill compared to all groups followed by (+ve) control group ,pumpkin seed group ,and nothing in creatine group respectively. However pumpkin seed group recorded the highest level in glycogen content in gastrocnemius muscle compared to all groups followed by creatine group ,corn silk group ,(+ve) control group ,and (-ve) control group. 
Mohammed $\mathrm{H}$.Haggag, et al

Table (1):

Phenolic contents in corn silk and pumpkin seeds

\begin{tabular}{c|c|c}
\hline Phenolic Compounds & Corn Silk $(\mathrm{mg} / \mathrm{kg})$ & Pumpkin seed $(\mathrm{mg} / \mathrm{kg})$ \\
\hline Syringic acid & 1.49 & 1.04 \\
\hline Vanillic acid & 2.06 & 8.13 \\
\hline p- Coumaric acid & 2.25 & 1.52 \\
\hline Quercetin & 2.74 & -- \\
\hline Cinnamic acid & 3.63 & -- \\
\hline Rutin & 4.13 & -- \\
\hline Chlorogenic & 4.30 & 7.34 \\
\hline Ferulic acid & 4.82 & -- \\
\hline Caffeic acid & 5.02 & 2.29 \\
\hline Caffeine & 5.15 & 10.16 \\
\hline Myricetin acid & 16.80 & -- \\
\hline Benzoic acid & 23.85 & 13.47 \\
\hline Salicylic acid & 34.75 & 5.19 \\
\hline Neringein & 61.88 & 22.88 \\
\hline Kampherol & 75.58 & 1.93 \\
\hline Ellagic & 417.10 & 71.91 \\
\hline Quinol & -- & 1.12 \\
\hline Gallic acid & -- & 1.72 \\
\hline Pyrogallol & -- & 1.78 \\
\hline Catechol & -- & 76.84 \\
\hline & &
\end{tabular}

Table (2):

The Antioxidant activity of corn silk and pumpkin seed

\begin{tabular}{l|c|c|c|c}
\hline \multirow{2}{*}{ SN } & \multicolumn{4}{|c}{$\%$ DPPH Radical-Scavenging Activity } \\
\cline { 2 - 5 } & $0.5 \%$ & $1.0 \%$ & $2.5 \%$ & $5 \%$ \\
\hline Corn Silk & 20.20 & 41.02 & 60.33 & 84.07 \\
\hline Pumpkin Seed & 31.79 & 46.53 & 88.50 & 99.68 \\
\hline
\end{tabular}

Table (3):

Effect of corn Silk, pumpkin seed and creatine on Body weight gain (BWG), feed intake (FI)and feed efficiency ratio (FER) of rats exposed to exhaustive test

\begin{tabular}{c|c|c|c|c}
\hline \multicolumn{2}{c|}{ Parameters } & FI g/day & BWG g & FER\% \\
\hline \multicolumn{1}{c|}{ Groups } & $(-\mathrm{ve})$ & $19.68 \pm 1.16^{\mathrm{c}}$ & $62.25 \pm 2.99^{\mathrm{b}}$ & $0.05 \pm 0.001^{\mathrm{a}}$ \\
\hline 1 & $(+\mathrm{ve})$ & $23.59 \pm 0.54^{\mathrm{c}}$ & $33.00 \pm 2.88^{\mathrm{c}}$ & $0.02 \pm 0.002^{\mathrm{b}}$ \\
\hline 2 & Corn Silk & $26.99 \pm 1.17^{\mathrm{b}}$ & $-56.00 \pm 2.54^{\mathrm{e}}$ & $-0.03 \pm 0.001^{\mathrm{d}}$ \\
\hline 4 & pumpkin & $20.00 \pm 0.88^{\mathrm{c}}$ & $-14.50 \pm 1.58^{\mathrm{d}}$ & $-0.01 \pm 0.001^{\mathrm{c}}$ \\
\hline 5 & Creatine & $28.03 \pm 0.47^{\mathrm{a}}$ & $72.75 \pm 2.21^{\mathrm{a}}$ & $0.04 \pm 0.001^{\mathrm{a}}$ \\
\hline
\end{tabular}

All value represented as mean \pm SD.

Means with different superscript are significantly different $(p<0.05)$. 
Egypt. J. of Nutrition and Health Vol. 15 No. 2 July (2020)

Table (4):

Effect of Corn Silk, Pumpkin Seed and Creatine on Aspartate Aminotransferase (AST), Alanine Aminotransferase (ALT) and Ammonia Level in rats exposed to exhaustive time test

\begin{tabular}{c|c|c|c|c}
\hline \multicolumn{2}{c|}{ Parameters } & $\begin{array}{c}\text { AST } \\
\mathrm{u} / \mathrm{l}\end{array}$ & $\begin{array}{c}\text { ALT } \\
\mathrm{u} / \mathrm{l}\end{array}$ & $\begin{array}{c}\text { Ammonia } \\
\mu \mathrm{g} / \mathrm{dl}\end{array}$ \\
\hline 1 & $(-\mathrm{ve})$ & $122.00 \pm 2.83^{\mathrm{d}}$ & $41.50 \pm 3.00^{\mathrm{b}}$ & $73.00 \pm 10.61^{\mathrm{c}}$ \\
\hline 2 & $(+\mathrm{ve})$ & $128.20 \pm 13.57^{\mathrm{c}}$ & $34.20 \pm 3.19^{\mathrm{c}}$ & $104.20 \pm 5.15^{\mathrm{b}}$ \\
\hline 3 & Corn Silk & $127.25 \pm 9.22^{\mathrm{c}}$ & $32.50 \pm 7.33^{\mathrm{c}}$ & $70.25 \pm 4.72^{\mathrm{c}}$ \\
\hline 4 & Pumpkin seed & $148.50 \pm 6.35^{\mathrm{b}}$ & $64.50 \pm 3.32^{\mathrm{a}}$ & $51.00 \pm 4.62^{\mathrm{d}}$ \\
\hline 5 & Creatine & $177.00 \pm 9.90^{\mathrm{a}}$ & $42.00 \pm 0.81^{\mathrm{b}}$ & $133.65 \pm 1.30^{\mathrm{a}}$ \\
\hline
\end{tabular}

All value represented as mean \pm SD.

Means with different superscript are significantly different $(p<0.05)$.

Table ( 5):

Effect of Corn Silk, Pumpkin Seed and Creatine on creatinine, urea, and uric acid level in rats exposed to exhaustive time.

\begin{tabular}{c|c|c|c|c}
\hline \multicolumn{2}{c|}{ Parameters } & $\begin{array}{c}\text { Creatinine } \\
\mathrm{mg} / \mathrm{dl}\end{array}$ & $\begin{array}{c}\text { Urea } \\
\mathrm{mg} / \mathrm{dl}\end{array}$ & $\begin{array}{c}\text { UA } \\
\mathrm{mg} / \mathrm{dl}\end{array}$ \\
\hline 1 & $(-\mathrm{ve})$ & $1.08 \pm 0.15^{\mathrm{b}}$ & $22.00 \pm 2.31^{\mathrm{b}}$ & $2.10 \pm 0.33^{\mathrm{c}}$ \\
\hline 2 & $(+\mathrm{ve})$ & $1.28 \pm 0.19^{\mathrm{a}}$ & $18.20 \pm 0.84^{\mathrm{c}}$ & $2.18 \pm 0.42^{\mathrm{c}}$ \\
\hline 3 & Corn Silk & $0.93 \pm 0.09^{\mathrm{c}}$ & $63.50 \pm 7.00^{\mathrm{a}}$ & $3.63 \pm 0.80^{\mathrm{b}}$ \\
\hline 4 & pumpkin & $0.86 \pm 0.09^{\mathrm{c}}$ & $25.25 \pm 2.63^{\mathrm{b}}$ & $3.28 \pm 0.05^{\mathrm{b}}$ \\
\hline 5 & Creatine & $1.05 \pm 0.17^{\mathrm{b}}$ & $23.50 \pm 1.73^{\mathrm{b}}$ & $4.03 \pm 0.23^{\mathrm{a}}$ \\
\hline
\end{tabular}

All value represented as mean \pm SD.

Means with different superscript are significantly different $(p<0.05)$.

Table (6):

Effect of Corn Silk, Pumpkin Seed and Creatine on Glucose and Creatine Kinase (CK) and lactate dehydrogenase level in rats exposed to exhaustive time

\begin{tabular}{c|c|c|c|c}
\hline \multicolumn{2}{c|}{ Groups } & $\begin{array}{c}\text { Glucose } \\
\mathrm{mg} / \mathrm{dl}\end{array}$ & $\begin{array}{c}\text { CK } \\
\mathrm{u} / \mathrm{l}\end{array}$ & $\begin{array}{c}\text { LDH } \\
\mathrm{u} / \mathrm{l}\end{array}$ \\
\hline 1 & $(-\mathrm{ve})$ & $106.01 \pm 5.42^{\mathrm{c}}$ & $24.50 \pm 5.74^{\mathrm{d}}$ & $2207.75 \pm 84.16^{\mathrm{a}}$ \\
\hline 3 & $(+\mathrm{ve})$ & $115.02 \pm 11.14^{\mathrm{b}}$ & $18.20 \pm 3.96^{\mathrm{d}}$ & $1416.40 \pm 91.50^{\mathrm{b}}$ \\
\hline 5 & Corn Silk & $96.50 \pm 01.91^{\mathrm{c}}$ & $676.25 \pm 18.89^{\mathrm{b}}$ & $787.25 \pm 3.77^{\mathrm{e}}$ \\
\hline 6 & Pumpkin seed & $97.00 \pm 03.83^{\mathrm{c}}$ & $1185.00 \pm 84.67^{\mathrm{a}}$ & $965.00 \pm 19.51^{\mathrm{d}}$ \\
\hline 9 & Creatine & $165.05 \pm 14.14^{\mathrm{a}}$ & $45.65 \pm 2.36^{\mathrm{c}}$ & $1301.50 \pm 52.80^{\mathrm{c}}$ \\
\hline
\end{tabular}

All value represented as mean \pm SD.

Means with different superscript are significantly different $(p<0.05)$. 
Table (7):

Effect of Corn Silk, Pumpkin Seed and Creatine on Malondialdehyde (MDA) and Glutathione-stransferase (GST) level in rats exposed to exhaustive time

\begin{tabular}{l|l|c|c}
\hline \multicolumn{2}{l|}{ Groups } & $\begin{array}{c}\text { MDA } \\
\mathrm{nmol} / \mathrm{ml}\end{array}$ & $\begin{array}{c}\text { GST } \\
\mathrm{u} / \mathrm{l}\end{array}$ \\
\hline 1 & $($-ve $)$ & $14.40 \pm 1.09^{\mathrm{b}}$ & $122.58 \pm 20.08^{\mathrm{b}}$ \\
\hline 2 & $(+\mathrm{ve})$ & $16.13 \pm 0.98^{\mathrm{a}}$ & $95.60 \pm 35.33^{\mathrm{d}}$ \\
\hline 3 & Corn Silk & $13.83 \pm 1.00^{\mathrm{b}}$ & $167.00 \pm 7.86^{\mathrm{a}}$ \\
\hline 4 & Pumpkin & $13.48 \pm 0.74^{\mathrm{b}}$ & $111.03 \pm 17.57^{\mathrm{c}}$ \\
\hline 5 & Creatine & $11.28 \pm 0.84^{\mathrm{c}}$ & $114.30 \pm 6.65^{\mathrm{c}}$ \\
\hline
\end{tabular}

All value represented as mean $\pm \mathrm{SD}$.

Means with different superscript are significantly different $(p<0.05)$.

Table (8):

The average exhaustive time on the treadmill for each of the experimental groups of rats (in minutes)

\begin{tabular}{c|c|c|c|c|c}
\hline Groups & $(-\mathrm{ve})$ & $(+\mathrm{Ve})$ & Corn Silk & Pumpkin seeds & Creatine \\
\hline Time $(\min )$ & - & 20 & 35 & 45 & 25 \\
\hline
\end{tabular}

Table (9)

Effect of corn silk, pumpkin seeds, and creatine on glycogen content in liver and gastrocnemius muscles after exposure and non-exposure to exhaustive treadmill test

\begin{tabular}{l|c|c|c|c|c|c}
\hline \multicolumn{1}{c|}{ Organs } & groups & $(-\mathrm{ve})$ & $(+\mathrm{ve})$ & Corn Silk & Pumpkin & Creatine \\
\hline \multirow{2}{*}{ Liver } & exhaustive & +++ & + & - & - & - \\
\cline { 2 - 7 } & $\begin{array}{c}\text { Non } \\
\text { exhaustive }\end{array}$ & +++ & ++ & +++ & + & - \\
\hline \multirow{2}{*}{$\begin{array}{l}\text { Gastrocnemius } \\
\text { muscle }\end{array}$} & exhaustive & + & ++ & - & + & +++ \\
\cline { 2 - 7 } & $\begin{array}{c}\text { Non } \\
\text { exhaustive }\end{array}$ & + & + & ++ & +++ & ++ \\
\hline
\end{tabular}

+++ Sever, ++ Moderate, + Mild, - Nil.

\section{Discussion}

In this experimental study, albino male rats were used to examine the effect of corn silk ,pumpkin seed, and creatine on fatigue after exercise by using treadmill that reached the exhaustive time, to determine the changes in body weight, liver enzymes, kidney function and oxidative stress .

The palatability of corn silk .pumpkin seed, and creatine powder affected the consumption and partly accounts for the trend in the final body weights of the animals. Exercise of sufficient intensity and duration can lead to the formation of reactive oxygen and nitrogen species (Fisher-Wellman and Bloomer, 2009), which when produced in amounts that overwhelm the antioxidant defense system may lead to a condition of "oxidative stress". Corn silk and pumpkin total phenolic contents which were seen in Tables ( 1 and 2 ) may be exhibited antioxidant activity by several mechanisms including a reduction in ischemia-reperfusion-induced oxidative stress (Loffredoet al., 2007\&Voleket al., 2002), a 


\section{Egypt. J. of Nutrition and Health Vol. 15 No. 2 July (2020)}

reduction in xanthine oxidase activity (Spierinet al., 2007)), and a free radical-scavenging activity as shown in Table(2) (vanellaet al.,2000).Increasing feed intake in +ve control group or all other treated groups whatever significant or not significant compared to -ve control group may be due to the training protocol which led to increase the intake of diet as a result of hunger.

Fiber content makes pumpkin seeds ideal for weight loss. This dense and heavy snack can keep the body satiated for quite a longer period of time. The fiber takes longer to digest, leaving rats full for longer and further keeps them away from bingeing on fattening foods. Other than this, pumpkin seeds is quite a good source of zinc, which can further help in boosting the body's metabolism. A sluggish metabolism can hinder body's weight loss efforts to a great extent. Hence, it is important to keep body's metabolism up by running (Sarine, 2018).

Lee et al., (2016) reported that experimental animals that received high-fat diet along with 100 $\mathrm{mg} / \mathrm{kg}$ of high maysin corn silk extract for 8 weeks showed significant reduction of body weight compared to the high-fat diet. Min et al., 2011 reported that administration of $100 \mathrm{mg} / \mathrm{kg} \mathrm{BW}$ and 400 $\mathrm{mg} / \mathrm{kg}$ BW of corn silk extract significantly lowered body weight of mice after 2 weeks of intake, which is consistent with the weight-reducing effect.

Results of the present study were in a line with Kreideret al., (1998)who indicated that $28 \mathrm{~d}$ of creatine supplementation during resistance/agility training promoted significantly greater gains in fat/bone-free mass. These findings support previous reports that creatine supplementation may increase total body weight and/or lean body mass.

The most sensitive and profitable diagnostic enzymes of the liver status are aminotransferases including aspartate aminotransferase (AST) and alanine aminotransferase (ALT) Generally, certain amounts of these enzymes are produced by liver cells, yet after liver damage, the liver cells increase the secretion of the enzymes and their plasma levels, (Terohid et al., 2015). The incidence of oxidative stress in the body has other negative effects, such as muscle fatigue, early restlessness impaired, decreased immune function, and muscle oxidation (Bloomer and Goldfarb, 2004).The results showed that 60 days of training protocol had slight alteration effect on serum levels of ALT and AST on +ve control and corn silk feeding groups exposed to exhaustive test. The lack of alteration is inconsistent with the findings of Kim et al.,(2007) and Ghasemnian et al.,(2020).Acute strenuous exercise induces oxidative stress and/or tissue damage in several tissues including skeletal muscle, liver, and kidney (Suzuki et al., 2003, Aoi et al .,2004 ,Suzuki ,2018). Davies et al., 1982 reported that exhaustive exercise increases reactive oxygen species (ROS) generation and induces tissue damage in liver and skeletal muscle. In agreement with Davies et al., we also observed that liver and skeletal muscle oxidative stress and a plasma marker of liver damage increased after exercise. It is well known that antioxidant capacity is increased by acute or chronic exercise (Yada et al., 2020). This research results were in a line with the above findings at table (4) especially corn silk group which showed great improvement compared with other treated groups.

Exhaustive treadmill running has been reported to increase the blood level of ammonia in humans (Wilkerson et al., 1977). Barnes et al., 1964) have reported that rats were forced to swim to exhaustion showed a significantly elevated level of ammonia. Ammonia $\left(\mathrm{NH}_{3}\right)$ is produced within contracting skeletal muscle by the breakdown of ATP and/or amino acids and is released into the circulation, thereby increasing plasma $\mathrm{NH}_{3}$ levels during exercise. Ammonia can cross the blood-brain barrier and has the potential to affect central neurotransmitter levels and central neural fatigue (Hargreaves and Lawrence, 2020). The speed endurance training session caused a strong and 


\section{Mohammed H .Haggag, et al}

prolonged exercise response, manifested by extremely high post-exercise blood ammonia and lactate concentrations as well as maximal heart rate.During high-intensity exercise, energy is mainly obtained from anaerobic sources. The main source of ammonia is the deamination of adenosine monophosphate to inosine monophosphate through the purine nucleotide cycle (Itoh et al., 1996, Wheeler and Lowenstein, 1997). An increase in ammonia concentration occurs predominantly after high-intensity exercise, where ammonia aids in stimulating glycolysis. With increasing fatigue, the level of ammonia biomarker increase, reflecting the physiological status (kantanistaet al., 2016).These results agree with the present study findings.As shown in the research results,corn silk play a whiteness role in the ammonia values impairment higher than pumpkin and creatine.

Oral creatine supplementation leads to an increase of creatine levels within the body. Creatine can be cleared from the blood by saturation into various organs and cells or by renal filtration (Cooper et al., 2012). Corn silk contain chemicals that work as diuretics, and can also help in reducing inflammations (Miriam et al., 2015).Canton et al .,1985 found that after using diuretics, the raise in plasma urea is due to increased tubular reabsorption presumably in the distal part of the nephron secondary to extracellular fluid volume depletion. This was in the line with present results and with Ohtaet al., 2020 who reported changes in blood pressure and metabolic adverse effects especially elevation of uric acid after treatment with diuretics and they attributed it to reduction in glomerular filtration rate.

Feeding corn silk extract increase the level of insulin and hence it lowers glucose level. some studies suggest its use as medicine for diabetics.(Guoet al., 2009) according to Mianto,(2000), the pancreatic enzyme synthesis including insulin may increase with physical exercise ,this was supported by (praphatsorn et al., 2010) that might explain the obtained results of glucose level in this study.

Seeds from Cucurbita contain bioactive compounds which have antifatigue activity and can elevate exercise performance. The seeds were said to have bioactivities such as hepatoprotection, anti-diabetes, anticancer, and anti-obesity properties (Wang, 2012). According to Bharti et al., 2013, Tocopherol isomers ( $\alpha, \beta, \gamma$, and $\delta$ ) from raw pumpkin seeds has been reported to be effective in the alleviation of diabetes through its antioxidant activities. In another study also on alloxan-induced diabetic rats demonstrate that polysaccharide from pumpkins has hypoglycemic effect (Xiong and Cao ,2001)This polysaccharide administered orally in alloxan-induced diabetic increase the body weight, reduced water intake, and reduced blood glucose levels of diabetic mice group (PerezGutierrez,2016).Gualanoet al.,(2010) Showed that creatine supplementation combined with exercise alleviated glycemic conditions in type 2 diabetes .

Release of creatine kinase $(\mathrm{CK})$ from muscle cells during exercise corresponds to the degree of permeability of cell membranes and their damage resulting, among other things, from an increase in the amount of free radicals formed during physical activity, leading to the peroxidation of cell membrane lipids (Banfiet al., 2012).After muscle-damaging exercise, the enzyme CK leaks from the muscle into the circulation. It is typical for athletes to have elevated CK during training (Mougios, 2007).

In the present study table (6)showed increasing in creatine kinase in pumpkin seed group among others groups ,those results in the similar line with ( AL-Zuhairet al., 1997)who suggested that pumpkin seeds oil was recorded ameliorated in creatine kinase levels while creatine group recorded lowest creatine kinase level. 


\section{Egypt. J. of Nutrition and Health Vol. 15 No. 2 July (2020)}

During exercise, when muscles exhaust the oxygen, pyruvate gets catalyzed into lactic acid by the lactate dehydrogenase enzyme. In this reaction, NADH oxidizes to NAD+. The availability of high intracellular concentrations of NAD is necessary to carry out the preparatory phase of glycolysis. The net ATP production of anaerobic glycolysis is only 2 ATP per glucose molecule as compared to oxidative phosphorylation, which produces 36 ATP per glucose molecule. LDH can also catalyze the dehydrogenation of 2-hydroxybutyrate, but it is the less preferred substrate for LDH than lactate (Adeva-Andanyet al., 2014), the results in table (6) shows an increase in LDH in creatine group which prove the previous hypothesis.

Table ( 7 ) shows decrease in MDA level with corn silk, pumpkin seed, and creatine groups compare with positive control group which reflect the great amount of Antioxidant compounds like phenolic acids, polyphenols and flavonoids scavenge free radicals such as peroxide, hydroperoxide or lipid peroxyl and thus inhibit the oxidative mechanisms that lead to degenerative diseases . this agrees with the report of( Bouzidet al., 2015).

Biomarkers to evaluate the antioxidant capacity include; glutathione (GSH), glutathione peroxidase (GPX), catalase, and the total antioxidant capacity (TAC) (Finsterer, 2012) GSTs are postulated as important detoxifying enzymes that catalyse reduced glutathione-dependent reactions involved in cellular protection against OS and toxic chemicals (Liavanera et al.,2020). GST results agree with the previous study (Ghahremanloo et al., 2017).which demonstrate that Pumpkin ameliorated oxidative stress and dyslipidemia in obese rats, leading to decrease cardiovascular disease risk in obesity. However, some studies showed different flavonoid synergists as most effective in hepatoprotection. Moreover, it has been reported that corn silk effectively increases antioxidant enzyme levels such as sodium dismutase and glutathione peroxidase (Hu and Deng, 2011)

The data in table (8) explained the major findings of the present study that rats fed on pumpkin seeds and exposure to exhaustive test recorded the longest period among all tested groups. This reflect Pumpkin seed and seed oil which are rich in natural source of phytosterols, proteins, polyunsaturated fatty acids, antioxidant vitamins, carotenoids and tocopherols, and various elements.These components provide many health benefits, (Perez- Gutierrez, 2016).High energy consumption during intense exercise may cause an imbalance between the oxidation and antioxidation systems, resulting in an increase in ROS and a reduction in antioxidant activities. These behaviors lead to enhanced ROS production. Oxidative stress is involved in both chronic fatigue and other fatigue related disorders (Barclay,and Hansel, 1991)Extreme physical stress could lead to excessive generation of ROS in the skeletal muscle which, in turn, results in peripheral fatigue, (Allen et al., 2008)

Glycogen is an important energy material that enables movement and provides adequate energy for muscle contraction. The Energy used reduces glycogen; meanwhile, an increase in hepatic glycogen can improve exercise endurance (Anandet al., 2012)

The histopathological examination to determine the glycogen contents in livers and muscles varied between all rat groups on exposure to exhaustive treadmill test indicated that rats in creatine group were depleted from glycogen content in the livers but muscle stored it in severe amount, The rats in corn silk group were depleted from glycogen content in livers and muscles. The results supported the finding of (Ivy et al., 2002) who tested the hypothesis that a carbohydrate-protein supplement would be more effective in the replenishment of muscle glycogen after exercise compared with a carbohydrate supplement of equal carbohydrate content or caloric equivalency when 


\section{Mohammed $\mathrm{H}$.Haggag, et al}

supplementing immediately and 2- hours post exercise, The results indicate that the co-ingestion of protein with carbohydrate will increase the efficiency of muscle glycogen storage when supplementing at intervals greater than 1-hour apart, or when the amount of carbohydrate ingested is below the threshold for maximal glycogen synthesis. These results have important implications for athletes who wish to limit their carbohydrate intake in an effort to control body weight and for those athletes who participate in sports that have very short recovery periods during competition such as basketball, ice hockey and soccer.

Steensberget al., 2002 suggest that pre-exercise glycogen content may Influence glucose uptake during subsequent exercise. However, this is only the case when delivery of substrates and hormones remains constant. When delivery of substrates and hormones is altered, the potential effect of glycogen on glucose uptake is negated. Evans et al.,(2019) These data suggest that the type, duration, and intensity of the resistance training program are important factors in determining the effects of resistance training on skeletal muscle glycogen content.

On the other hand at the present study, the supplemented groups, not exposed to exhaustive treadmill test preserves the glycogen content either in liver or muscle, and that met agreement with hypothesis that decreased use of muscle causes it to become much less metabolically efficient; unfortunately, this de adaptation becomes apparent within a few days after cessation of exercise. Other factors induced by endurance training include changes in cardiac output, increases in capillary density, and increases in glycogen stores (Baynes and Dominiczak, 2019).

\section{Conclusions}

Findings of this study prove that corn silk and pumpkin seeds were a good source of flavonoid which help to scavenge the oxidative stress substances, creatine recorded the largest glycogen quantity in gastrocnemius muscles among supplemented groups, but it causes an elevation of ammonia, and AST levels on the groups exposed to exhaustive time test, so more studies for creatine efficacy on skeletal muscle is recommended. Moreover, it could be recommended that corn silk and pumpkin seeds have the ability to eliminate physical fatigue and prolong the training period without fatigue. 
Egypt. J. of Nutrition and Health Vol. 15 No. 2 July (2020)

\section{References}

Adeva-Andany, M., López-Ojén, M., Funcasta-Calderón, R., Ameneiros-Rodríguez, E.andDonapetry-García, C. (2014):

Comprehensive review on lactate metabolism in human health. Mitochondrion. Jul; 17:76-100.

Allen,D.G, Lamb,G.D.and Westerblad,H. (2008):

Skeletal muscle fatigue: cellular mechanisms. Physiol Rev; 88(1):287-332.

Al-Zuhair, H., Abdel-Fattah, A. A. and Abd el Latif, H. A. (1997):

Efficacy of Simvastatin and Pumpkinseed Oil in The Management of Dietary-induced Hypercholesterolemia, Pharmacol.Res., 35(5), 403-408.

Anand, T., Phani. Kumar, G. andPandareesh, M.D. (2012):

Effect of bacoside extract from Bacopamonniera on physical fatigue induced by forced swimming.Phytother Res.; 26(4):587-593.

Andritsos, N.,Dalampakis, P. and Kolios, N. (2003):

Use of geothermal energy for tomato drying.GeoHeat Center Quarterly Bulletin March, 70(4): 9-13.

Aoi, W., Naito, Y., Takanami, Y., Kawai, Y., Sakuma, K., Ichikawa, H. and Yoshida, N.(2004):

Oxidative stress and delayed-onset muscle damage after exercise. Free Radical. Biol. Med. $37,480-487$.

Araújo, M., Moura, L., Vieira J, R., Marcelo, C., Dalia, R., Sponton, A.,Ribeiro, C.and Alice, M. (2013):

Creatine supplementation and Oxidative stress in ratliver. Journal of the International Society of Sports Nutrition. 10:54.

Banfi, G., Colombini, A., Lombardi, G. andLubkowska, A. (2012):

Metabolic markers in sports medicine. Advances in Clinical Chemistry. ; 56:1-54. doi: 10.1016/b978-0-12-394317-0.00015-7.

Barclay, J.K. and Hansel, M. (1991):

Free radicals may contribute to oxidative skeletal muscle fatigue. Can J PhysiolPharmacol.; 69(2):279-284.

Barnes, R.H., Labadan, B.A., Siyamoglu, B. and Bradfield, R.B. (1964):

Effects of exercise and administration of aspartic acid on blood ammonia in the rat. Am $\mathrm{J}$ Physiol ;(207):1242-6.

Baynes, J.W. and Dominiczak,M.H. (2019): Medical biochemistry .EL SEVIER 5TH ed .p559, 562. 


\section{Mohammed $\mathrm{H}$.Haggag, et al}

Bharti, S.K., Kumar, A., Sharma, N.K., Prakash, B.O. and Jaiswal, S.K. (2013):

Tocopherol from seeds of Cucurbita pepo against diabetes: Validation by in vivo experiments supported by computational docking. J Formosan Med Assoc 112: 676-690.

Bloomer, R.J. and Goldfarb, A.H. (2004):

Anaerobic exercise and oxidative stress: a review. Can J Appl Physiol.; 29(3):245-63. doi: 10.1139/h04-017.

Brand-Williams, W., Cuvelier, M.E. and Berset, C. (1995):

Use of a free radical method to evaluate antioxidant activity. LWT Food Sci.Techno. 28; 2530.

Bouzid, M.A., Hammouda,O., Matran,R. and Robin,S. (2015):

Influence of physical fitness on antioxidant activity and malondialdehyde level in healthy older adults. Appl Physiol Nutr Metab; 40(6):582-9.

Canton, A., fuiano,G., Conte,G. and Terrible,M. (1985):

Mechanism of increased urea after diuretics therapy in uraemic patients .Mars; 68(3):256-61.

Ching, w., Chun, w., Chuang, H., Wei, D.T., Min, Z., Li, W., Chen, F. and Chang, CH. (2015):

Effect of Curcumin Supplementation on Physiological Fatigue and Physical Performance in Mice. Nutrients. 7: 905-921.

Cooper, R., Naclerio,F., Allgrove,J. and Jimenez,A. (2012):

Creatine supplementation with specific view to exercise/sports performance: an update. Journal of the International Society of Sports Nutrition; 9(33).

Davies, K.J.,Quintanilha, A.T., Brooks, G.A. and Packer, L.(1982):

Free radicals and tissue damage produced by exercise. Biochem. Biophys. Res. Commun., 107, 1198-1205.

Davis, M., Murphy, A., Carmichael, M. D. and Davis, B. (2009):

Quercetin increases brain and muscle mitochondrial biogenesis andexercise tolerance. Am J PhysiolRegullntegr Comp Physiol.296:1071-1077.

Ebrahimzadeh, M.A.,Pourmorad, F. and Hafezi, S. (2009):

Antioxidant activities of Iranian corn silk. Turkish J Biol. 32:43-49.

Evans, P.L., McMillin, S.L. andWeyrauch, L.K. (2019):

Regulation of Skeletal Muscle Glucose Transport and Glucose Metabolism by Exercise Training. Nutrients; 11, 2432.

Finsterer, J. (2012):

Biomarkers of peripheral muscle fatigue during exercise. BMC Musculo skelet Disord; 13: 218. 


\section{Egypt. J. of Nutrition and Health Vol. 15 No. 2 July (2020)}

Finsterer, J. and Drory, V.E. (2016):

Wet, volatile, and dry biomarkers of exercise-induced muscle fatigue. BMC Musculos kelet. Disord., 17, 40.

Fisher-Wellman, K. and Bloomer, R.J. (2009):

Acute exercise and oxidative stress: a 30 year history. Dyn Med; 8:1.

Fossati, P., Prencipe, L. and Berti, G. (1980):

Enzymatic colorimetric method of determination of uric acid in serum. Clin. Chem.; (18)499-502.

Gama, M.S. (2011):

Efeitos da creatinasobredesempenhoaeróbio: umarevisãosistemática. RevistaBrasileira de Nutrição Esportiva. 5:182-190.

Ghahremanloo, A., Hajipour, R., Hammati, M. and Moossavi,M. (2017):

the beneficial effect of pumpkin extract on atherogenic lipid, insulin resistance and oxidative stress statues in high-fat diet -induced obese rats. Journal of Complementary and Integrative Medicine; 15: (2).

Ghasemnian,A., Iddehloei, Z., Rahmani, A. and Usefpour,M. (2020):

Effects of ginger along with exercise training on serum levels of ALT and AST liver enzymes and malondialdehyde and the activity of liver tissue superoxide dismutase in male Wistar rats Journal of Shahrekord University of Medical Sciences. ; 22(2):67-73.

Gualano,B., painneli,V., Roschel, H., giannini,G.A. andNeves, M.(2010): creatine in type 2 diabetes: A Randomized, Double-Blind, Placebo-Controlled Trial. Journal of the medicine and Science in Sports and Exercise; 43(5):770-8.

Guo, J., Liu, T., Han, L. and Liu, Y. (2009):

The effects of cornsilk on glycaemic metabolism, Pubmed, Nutr Metlab London), doi: 10.1186/1743-7075-6-47.

Habig, W., Pabst, M.and Jakoby,W.J.(1974):

Glutathione S-transferases. The first enzymatic step in mercapturic acid formation J.biol.chem.249, 7130-7139.

Hargreaves, M. and Lawrence, L. S.(2020):

Skeletal muscle energy metabolism during Exercise. Nature Metabolism;2. 817-828.

Hu, Q. L., Zhang, L. J., Li, Y. N., Ding, Y. J. and Li, F. L. (2010):

Purification and anti-fatigue activity of flavonoids from corn silk. International Journal of Physical Sciences; 5(4); 321-326.

Hu, Q.L. and Deng, Z.H. (2011):

Protective effects of flavonoids from corn silk on oxidative stress induced by exhaustive exercise in mice. African journal of biotechnology; 10(16). 


\section{Mohammed H .Haggag, et al}

Itoh H, Ohkuwa,T., Yamazaki,Y. andMiyamura, M.(1996):

Human blood lactate and ammonia levels after supramaximal uphill and downhill running. Nagoya J Med Sci. 1996; 59: 135-142.

Kantanista, a., Kusy,K. and Dopierała,K.(2016):

Blood lactate, ammonia and kinematic indices duringa speed-endurance training session in elite sprinters. TRENDS in Sport Sciences; 2(23): 73-79

Kaplan,A. et al. (1984):

Urea ClinChemthe C.V. Mosby Co. St Louis. Toronto. Princeton 1257-1260

Kim, H.J., Lee, Y.H. and Kim,C.K.(2007):

Biomarkers of muscle and cartilage damage and inflammation during a $200 \mathrm{~km}$ run. Eur J AppIPhysiol.; 99(4):443-7. doi: 10.1007/s00421-006-0362-y.

Kreider, R. B., Ferreira, M. and Wilson, M. (1998):

Effects of creatine supplementation on body composition, strength, and sprint performance. Medicine \& Science in Sports \& Exercise; 30 - (1) - pp 73-82.

Lee, E.Y., Lim, S. K., Jung,H. K., Hwan,M. K., Wha, A. H. and Kyoung, W. K. (2016):

High maysin corn silk extract reduces body weight and fat deposition in C57BL/6J mice fed high-fat diets. Nutrition Research and Practice; 10(6):575-582.

Liavanera, M., Delgado-bermudez, A. and Olives,S. (2020):

Glutathione S-Transferase play acrucial role in mitochondrial function, plasma membrane stability and oxidative regulation of mammalian sperm.

Loffredo, L., Marcoccia, A., Pignatelli, P. and Andreozzi, P. (2007):

Oxidative-stress-mediated arterial dysfunction in patients with peripheral arterial disease. Eur Heart J; 28:608-612.

Ivy, J.L., Goforth, H.W., Damon, B.D., McCauley, T.R., Parsons, E.C. and Price, T.B. (2002):

Early post exercise muscle glycogen recovery is enhanced with a carbohydrate-protein supplement. Journal of Applied Physiology 93, 1337-1344.

Minato, K. (2000):

The effect of chronic exercise on the rat Pancreas. Int J Pancreatol ; 27:151-6.

Min, O.J., Sharma, B.R., Park, C.M. and Rhyu, D.Y.(2011):

Effect of myadis stigma water extract on adipogenesis and blood glucose in 3T3-L1 adipocytes and db/db mice. Korean J Pharmacogn; 42:201-8.

Miriam,j.G., Induja,T.A., Manoj, J.B. andShivasamy, M.S.(2015):

Recent trends in effective utilization of by-product corn,Indain Journal of Science,22(76),1826.

Mougios, V. (2007):

Reference intervals for serum creatine kinase in athletes. Br J Sports Med 41: 674-678, 
Egypt. J. of Nutrition and Health Vol. 15 No. 2 July (2020)

Murray, R.L. and Kaplan, A .(1984):

Creatinine Clin Chemthe C.V. Mosby Co. St Louis. Toronto. Princeton; 1261-1266

Ohkawa, H., Ohishi, W. and Yagi,K. (1979):

Serum malondialdehyde clinbiochem. 95,351.

Ohta, Y., Kamide, K., Hanada, H. and Morimoto, S. (2020):

Genetic factors associated with elevation of uric acid after treatment with thiazide-like diuretic in patients with essential hypertension.mar;43(3):220-226.

Patel,S.(2013):

Pumpkin (Cucurbita sp.) seeds as nutraceutic: a review on status quo and scopes. Mediterr $\mathrm{J}$ Nutr Metab. 6 (3): 183-189.

Perez -Gutierrez,R.M. (2016):

Review of Cucurbita pepo (Pumpkin) its Phytochemistry and Pharmacology. Med chem 6: 012-021. doi:10.4172/2161-0444.1000316.

Praphatsorn, P., Thong-Ngama, D., Kulaputanaa,O. and Klaikeawb,N.(2010):

Effects of intense exercise on biochemical and histological changes in rat liver and pancreas. Asian Biomedicine; 4. (4); 619-625.

Sarine, D. (2018):

Pumpkin Seeds For Weight Loss: Switch Over To This Healthy Snack To Lose Weight Healing Foods. DK Publishing House

Schumann ,G. (2002):

IFCC reference procedure for aspartate aminotransferase; CCLM .40(7):725-733.

Sendecor,G. and Cochran,w.(1986):

Statistical methods 7 thed,iowa state university press,Ames,USA,90.

Sherwin, J.E. (1984):

Liver function. In:kaplan LA, PESCE AJ, eds. Clinical chemistry, theory,analysis, and correlation. St louis: mosby;:420- 438.

Spierin, B.A., Kraemer, W.J., Vingren,J.L.andHatfield,D.L. (2007):

Responses of criterion variables to different supplemental doses of L-carnitine L-tartrate.J Strength Cond Res ;21:259.

Steensberg,A., van Hall,G., Keller, C. and Osada,T.(2002):

Muscle glycogen content and glucose uptake during exercise in humans: influence of prior exercise and dietary manipulation. Journal of Physiology, 541. (1). 273-281.

Suzuki, K. (2018):

Involvement of neutrophils in exercise-induced muscle damage. Gen. Intern. Med. Clin. Innov, 3, 1-8. 


\section{Mohammed H .Haggag, et al}

Suzuki, K., Nakaji, S., Yamada, M., Liu, Q., Kurakake, S., Okamura, N.and Kumae, T. (2003): Impact of a competitive marathon race on systemic cytokine and neutrophil responses. Med. Sci. Sports Exerc. , 35, 348-355.

Terohid, S., Mirazi, M. and Sarihi, A. (2015):

Study of hepatoprotective effect of Malvaneglecta L. hydroethanolic leaf extract in male rat Induced with carbon tetrachloride. Journal of Cell \& Tissue.; 6(1):31-42.

Tietz,N.W. (1976):

Fundamentals of clinical chemistry .2nd ed W.B Saunders Philadelphia.

Trinder, P. (1969):

Determination of Glucose in Blood Using Glucose Oxidase with an Alternative Oxygen AcceptorAnn.clin. Biochem.6:24.

Vanella, A., Russo, A., Acquaviva, R., Campisi, A., Di Giacomo, C., Sorrenti, V. and Barcellona, M. (2000):

L-propionyl-carnitine as superoxide scavenger, antioxidant, and DNA cleavage protector. Cell BiolToxicol; 16:99-10.

Vassault,A. et al. (1986):

Lactate dehydrogenase, UV-method with pyruvate and NADHAnn.Biol. Clin., 44,686.

Wan, P.F., Sheng, Z.L., Han, Q., Zhao, Y.L., Cheng, G.D. and Li, Y.H.(2014):

Enrichment and purification of total flavonoids from Flospopuli extracts with macroporous resins and evaluation of antioxidant activities in vitro. J. Chromatogr. B, 945: 68-74.

Wang, S.Y., Huang, W.C., Liu, C.C., Wang, M.F., Ho, C.S. and Huang, W.P. (2012):

Pumpkin (Cucurbita moschata) fruit extract improves physical fatigue and exercise performance in mice. Molecules. 17:11864-11876.

Weissman, M. and Klein,B. (1958):

Evaluation of glucose determination in untreated serum samples. clin chem.4:420-422. 27.

Wheeler, T.J. and Lowenstein, J.M. (1997):

Creatine phosphate inhibition of adenylate deaminase is mainly due to pyrophosphate. J Biol Chem. 10: 1484-1486.

Wilkerson, J.E., Batterton, D.L. and Horvath, S.M. (1977):

Exercise-induced changes in blood ammonia levels in humans. Eur $\mathrm{J}$ Appl Physiol Occup Physiol;(37):255-63.

Xiong, X. and Cao, J. (2001):

Study of extraction and isolation of effective pumpkin polysaccharide component and its reducing glycemia function. Chinese $\mathrm{J}$ Modern Application Pharm 18: 662-664.

Yada, K., Arwyn, L.R., Oginome., N. and Suzuki,K. (2020): 
Egypt. J. of Nutrition and Health Vol. 15 No. 2 July (2020)

Effect of Acacia Polyphenol Supplementation on Exercise-Induced Oxidative Stress in Mice Liver and Skeletal Muscle.J Antioxidants mdpi , 9, 29; doi:10.3390/antiox9010029.

\section{دراسة مقارنة بين حرير الذرة ربذور اليقطين و الكرياتين لاختبار كفاءة النشاط البدنى في الجرذان}

\section{محمد حمدى حجاج : نعيم محمد رابح: اسماء زايد محمد}

قسم التغذية و علوم الاطعمة ـ كلية الاقتصاد المنزلى ـ جامعة حلوان ـ القاهرة - جمهورية مصر العربية

$$
\text { الملخص العربي }
$$

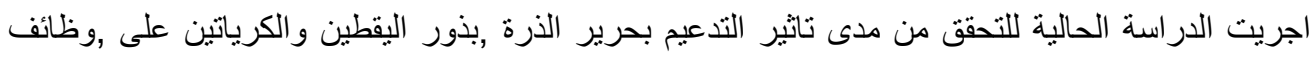
الكلى , وظائف الكبد ,الجلوكوز ,الكرياتين كاينيزواللاكتات دى هيدروجينيز على ذكور الفئران الددربة البالغة

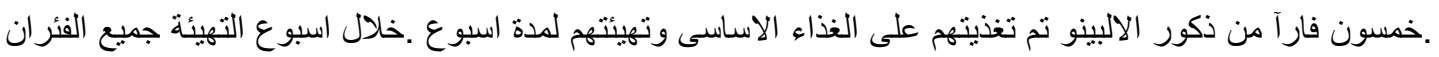

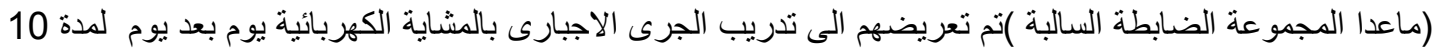

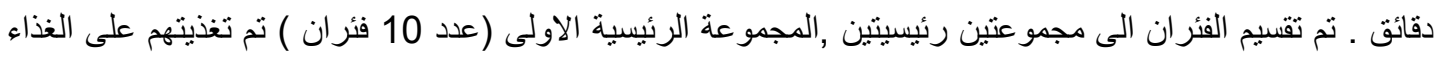

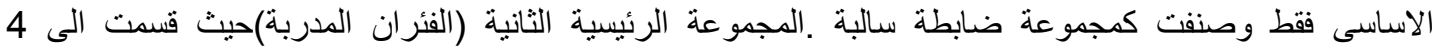

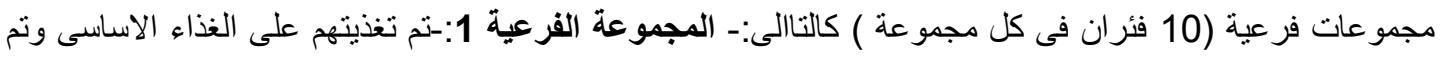

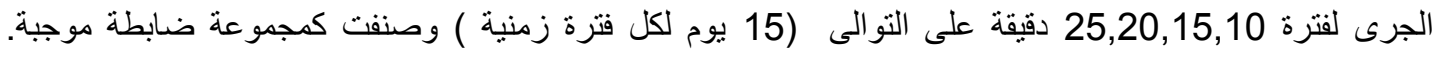

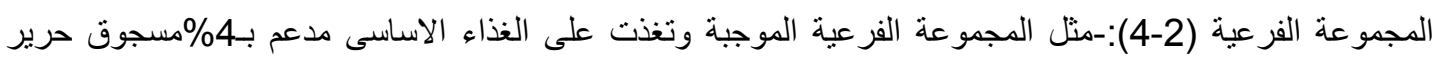

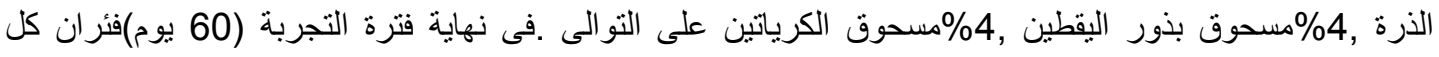

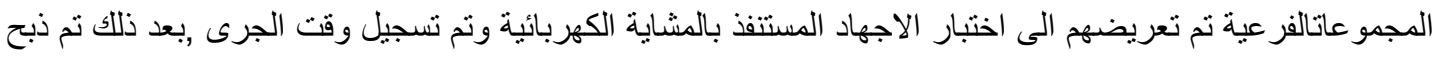

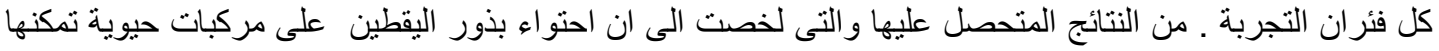

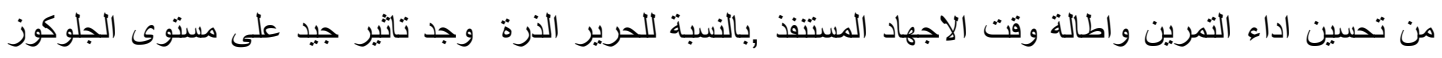

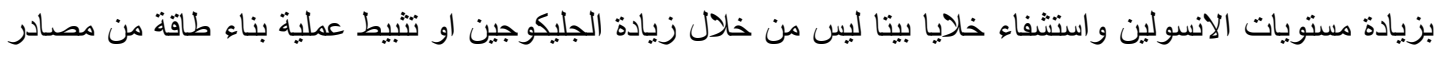

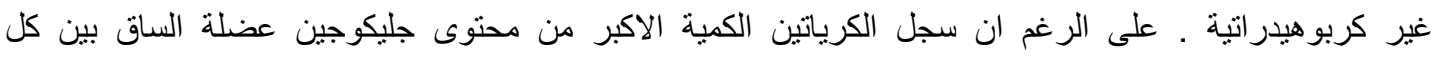

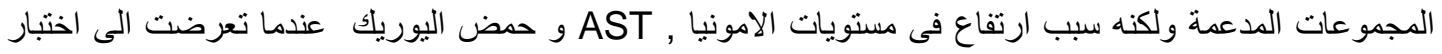

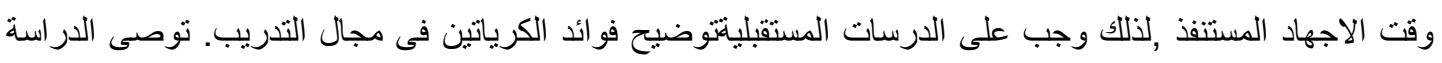

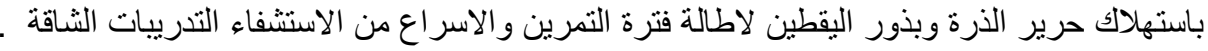
الكلمات المفتاحية:- حرير الذرة , بذور اليقطين, تدعيم الكرياتين ,كرياتتين , مشاية كهربائية , التمرين . 